\title{
Low-cost infrared thermography in aid of photovoltaic panels degradation research
}

\section{Termografía infrarroja de bajo costo como soporte para la investigación sobre degradación} de paneles fotovoltaicos

\author{
Miguel Alberto Dávila-Sacoto (iD) 1 , Luis Hernández-Callejo (iD ${ }^{2 *}$, Víctor Alonso-Gómez (iD ${ }^{3}$, Sara \\ Gallardo-Saavedra (iD) ${ }^{2}$, Luis González-Morales (iD) 1 \\ ${ }^{1}$ Facultad de Ingeniería, Universidad de Cuenca, Campus Central. Av 12 de Abril \&. C. P. 010104. Cuenca, Ecuador. \\ ${ }^{2}$ Departamento de Ingeniería Agrícola y Forestal, Universidad de Valladolid. UVa-Campus Duques de Soria. C. P. 42004. \\ Soria, España. \\ ${ }^{3}$ Departamento de Física Aplicada, Universidad de Valladolid. UVa-Campus Duques de Soria. C. P. 42004. Soria, España.
}

\section{CITE THIS ARTICLE AS:}

M. A. Dávila, L. Hernández, V.

A. Gómez, S. Gallardo and L.

González. "Low-cost infrared thermography in aid of photovoltaic panels degradation research", Revista Facultad de Ingeniería Universidad de Antioquia, no. 101, pp. 20-30, Oct-Dec 2021. [Online]. Available: https: //www.doi.org/10.17533/ udea.redin. 20200689

\section{ARTICLE INFO:}

Received: November 12, 2019 Accepted: Jun 09, 2020

Available online: Jun 09, 2020

\section{KEYWORDS:}

Thermography; low cost; thermal camera; image processing; temperature sensor

Termografía; bajo costo; cámara térmica; procesamiento de imágenes; sensor de temperatura
ABSTRACT: The analysis of PV solar panels deterioration allows researchers to know the health status of a panel in order to determine the overall functioning of a PV solar farm. A part of this analysis is performed by thermography, generally using professional and expensive equipment. This article presents a validation for the use of low-cost thermal imaging cameras, reviewing the relative error that can be obtained through scattering, contour analysis and three-dimensional meshes. The procedure is validated by analysis of I-V/P-V curves and a temperature sensor matrix, reaching errors less than $10 \%$ with cameras with less than 500USD.

RESUMEN: El análisis del deterioro de paneles fotovoltaicos permite a los investigadores conocer el estado de salud de un panel con el objetivo de determinar el funcionamiento global de una granja fotovoltaica. Una parte de este análisis se realiza mediante termografía, utilizando generalmente equipos profesionales y de costos elevados. Este artículo se presenta una validación para el uso de cámaras termográficas de bajo costo, revisando el error relativo que se puede obtener mediante análisis de dispersión, contorno y mallas tridimensionales. El procedimiento es validado mediante análisis de curvas I-V/P-V y una matriz de sensores de temperatura, llegando a errores menores del $10 \%$ con cámaras con inferiores a 500USD.

\section{Introduction}

Thermography is a common technique in Operation and Maintenance (O \& M) of PV solar farms used for detecting hot spots in PV solar panels caused by deterioration of

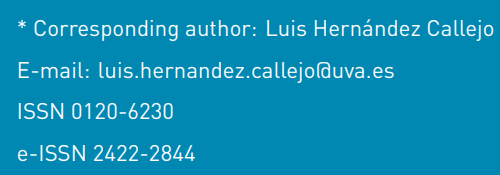

internal cells or by partial shading [1].

Hot spots can compromise short-term panel performance and long-term damage if not treated properly. Infrared thermography (IR thermography) in PV solar panels is a technique that generally uses high-resolution infrared thermal cameras in order to obtain detailed information on the temperature of each cell in a PV panel. High-resolution IR cameras are expensive equipment due to their special thermal capabilities and accuracy, providing researches 
a high-quality image to analyze panel's degradation. High-resolution and professional grade thermal cameras are expensive, which is an inconvenience for low-budget research institutes or students aiming to thermal analysis in PV solar panels. Nevertheless, low-cost thermal cameras do exist in the market, being an interesting alternative for thermal analysis of small-scale PV power plants and research laboratories, providing information that allows initial action to be taken in case of any anomaly observed. This paper shows the use of low-cost cameras for IR thermography PV solar panels under normal operation, most important features and disadvantages are detailed, emphasizing its cost. Analysis of the images obtained with both temperature tables, static images, and thermocouple measurements is carried out.

Analysis discussed in this document are an extension of previous work "Detecting hot spots in photovoltaic panels using low-cost thermal cameras" presented on the Smart Cities - II Iberoamerican Congress on Smart Cities (ICSC-CITIES 2019).

\section{Thermal cameras}

\subsection{Cameras used for thermography in PV systems}

Thermal cameras are devices that capture the IR radiation emitted by heat on an object [2] converting the data from the camera's sensor into an image that represents the temperature pattern of the area of interest (AOI). IR Thermal Analysis is a non-invasive technique (no disconnection required) used to observe the temperature of an object, equipment or machinery to verify the temperatures under operation. As for PV systems is concerned, IR thermography is used to identify failures in PV cells or in electrical connections [3-9], providing relevant information that facilitates the 0 \& $M$ of $P V$ sites. However, IR thermal cameras normally used in PV thermal analysis are expensive. Table 1 shows the most important characteristics and cost of a set of thermal imaging cameras commonly used for PV analysis.

Options presented in Table 1 are considered high-resolution or professional thermal cameras. Sensor's resolution used on these models allows detailed analysis of thermal patterns. Regarding cost and resolution relationship, most expensive options have a smaller cost per resolution ratio. Among them, the Flir TAU2 camera stands out with a lower cost per pixel.

\subsection{Low-cost infrared thermal cameras}

Low-cost IR thermal cameras with technical characteristics suitable for its usage in thermography do exist in the market and are a viable option to consider. Low-cost IR thermal cameras shown in Table 2 are used in this paper.

Prices in Table 2 are taken from renowned online stores in the US without shipping. These low-cost IR thermal cameras have prices below $\$ 500$, which make them easily accessible compared to more expensive models. It is noteworthy that the Flir TG167 camera features similar to the Flir i3 and CAT s60. However, the Flir TG167 may be considered more like an infrared thermometer with a thermal camera since the image temperature shown on the display corresponds to the reading of the built-in microbolometer, rather than an array of thermal sensors.

In Figure 1, images captured with low-cost IR thermal cameras under study are observed. All cameras offer similar behaviors, but the higher resolution Flir One Pro camera presents a sharper and more edge defined image than the lower resolution Cat S60 camera. On the other hand, the FLIR TG167 image has a very low image resolution, but this often can be seen as an advantage as embedded image processing is concerned llower resolution means fewer processing power needed).

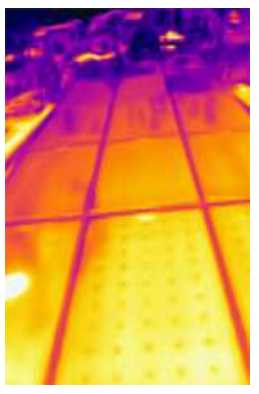

(a)

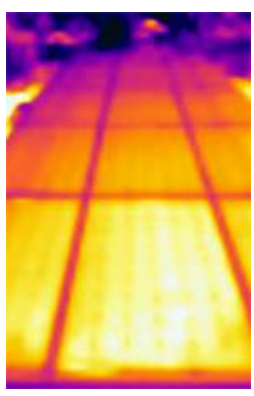

(b)

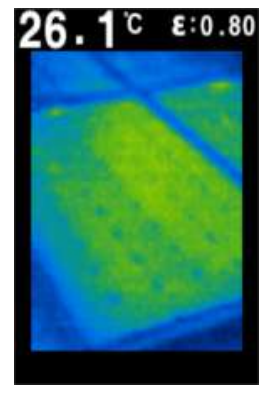

(c)
Figure 1 IR thermal image of a PV panel captured by (a) FLIR One Pro camera, (b) Caterpillar Cat S60 camera, (c) FLIR TG167

Table 3 shows a comparison of the cameras used and the limitations found according to on-site tests.

High-end or professional-grade IR thermal cameras are designed specially to perform in challenging environments and record high-resolution high-accuracy images, ensuring confidence and repeatability on the data obtained. IP rating on high-end cameras is a very important advantage for its use in harsh environments. Also, they often have a higher framerate enabling smooth video analysis. Other technical advantages include industrial communication protocols, interchangeable lenses and more. High-end cameras are mainly used by 
Table 1 Features and prices of IR thermal cameras used in the thermographic analysis in photovoltaic panels

\begin{tabular}{ccccc}
\hline Brand & Flir & Flir & Testo & Flir \\
\hline Model & SC655 & TAU2 & $870-2$ & i3 \\
Thermal image quality (pixels) & $640 \times 480$ & $640 \times 512$ & $160 \times 120$ & $60 \times 60$ \\
Thermal sensitivity & $<0.1^{\circ} \mathrm{C}$ & $<0.1^{\circ} \mathrm{C}$ & $<0.1^{\circ} \mathrm{C}$ & $<0.15^{\circ} \mathrm{C}$ \\
Price (USD) & $\$ 26,990.00$ & $\$ 6,000.00$ & $\$ 2,528.00$ & $\$ 1,295.00$ \\
Price/Resolution (USD/pixel) & 0.0875 & 0.0183 & 0.1316 & 0.3597 \\
\hline
\end{tabular}

Table 2 Main features and prices of low-cost IR thermal cameras

\begin{tabular}{cccc}
\hline Brand & Caterpillar & Flir & Flir \\
\hline Model & CAT s60 & One Pro & TG167 \\
Thermal image quality (pixels) & $80 \times 60$ & $160 \times 120$ & $80 \times 60$ \\
Thermal sensitivity & $<0.15^{\circ} \mathrm{C}$ & $<0.15^{\circ} \mathrm{C}$ & $<0.15^{\circ} \mathrm{C}$ \\
Price (USD) & $\$ 428.00$ & $\$ 388.92$ & $\$ 399.99$ \\
Price/Resolution (USD/pixel) & 0.089 & 0.015 & 0.083 \\
\hline
\end{tabular}

Table 3 Comparison of characteristics of low-cost thermal cameras

\begin{tabular}{cccc}
\hline Camera & Flir One Pro & Cat S60 & Flir TG167 \\
\hline Temperature table (metadata) & Yes & Yes & No \\
& USB-C with Android / & Included inside the & No connection. Images \\
Connection & iOS smartphones & smartphone & stored in microSD card \\
Weight & $36.5 \mathrm{~g}$ & $223 \mathrm{~g}$ & $312 \mathrm{~g}$ \\
Outdoor use & No & No & Yes \\
Drone use & Yes (lighter) & Yes & No \\
\hline
\end{tabular}

research institutes or by industries with large budgets, that can contact the manufacturer directly for support or even pay for it.

On the other hand, low-cost thermal cameras are designed to perform in less challenging environments, while recording high or medium resolution images, with accuracy and repeatability depending on the model and manufacturer. Low-cost IR thermal cameras could be used for thermal inspection on small or mid-sized solar farms but considering their IP rating limitations. A very important advantage of low-cost thermal cameras is low energy consumption, very important to embedded systems and UAVs, also they often have standard and commercial communication protocols. Low-cost alternatives are also becoming widely used by hobbyists, students and the open-source community, meaning a large number of people behind its use and development. This advantage is important to independent researchers or small research groups because when developing solutions or carrying out thermal analysis, technical support is an important issue, especially if the camera manufacturer is from another country or speaks a different language than the user. With low-cost cameras, it is possible to find support within users.

Table 4 shows a technical comparison or four high-end thermal cameras, and the three low-cost alternatives discussed in this document based on power, framerate, precision and IP rating. It is observed that low-cost cameras tend to have a lower power consumption, framerates and accuracy. This could be a problem regarding the application characteristics, for example, if a thermal analysis needs a real-time temperature monitoring system with instant readings, high-framerate cameras are the best choice.

\subsection{Thermal cameras comparison methodology}

In order to make the comparison between low-cost cameras, the procedure used is based on capturing images of panels with and without failures to observe if the camera is capable of finding a fault properly. In addition, a comparison is made of the images obtained from the camera, this is the image in jpg format or static image which contains the information of the pixel values in RGB format, and the thermal image or image with metadata which contains the information of the temperature values of each pixel. 
Table 4 Power, Framerate, Accuracy and IP rating comparison of High-End and Low-cost thermal cameras

\begin{tabular}{c|ccccccc} 
Parameter & Low-Cost & \multicolumn{5}{c}{ High-End } \\
& Flir One Pro & Cat S60 & Flir TG167 & Testo 870-2 & Flir i3 & Flir SC655 & Flir Tau 2 \\
\hline Power [W] & 1.1 & 1.2 & 1.2 & 2.3 & 1.6 & 24 & 1.3 \\
Framerate [Hz] & 8.7 & 8.7 & 9 & 9 & 9 & 50 & 60 \\
Accuracy & $+-3^{\circ} \mathrm{C} 5 \%$ & $+-5^{\circ} \mathrm{C} 5 \%$ & $+-1.5^{\circ} \mathrm{C} 1.5 \%$ & $+-2^{\circ} \mathrm{C} 2 \%$ & $+-2^{\circ} \mathrm{C} 2 \%$ & $+-2^{\circ} \mathrm{C} 2 \%$ & $+-2^{\circ} \mathrm{C} 2 \%$ \\
IP rating & No & IP68 & IP40 & IP54 & IP54 & IP67 & IP67 \\
\hline
\end{tabular}

\section{Low-cost IR Thermal Cameras in PV panel thermography}

Low-cost IR thermal cameras in Table 2 were used to perform a thermographic analysis of the PV solar farm described in [10]. As a summary, University of Cuenca's solar farm has $35 \mathrm{kWp}$ installed, with 80 polycrystalline and 80 monocrystalline PV panels, and has been under production since 2016. After manual inspection of the 160 solar panels, two were found with hot spots. One of these anomalies captured with a Flir One Pro camera and processed with the Flir Tools software [11] is shown in Figure 2. The image corresponds to the first panel with a hot spot. Two points identified as $\mathrm{T} 1$ and $\mathrm{T} 2$ are observed (see Figure 2a), with temperatures of $38.2 .0^{\circ} \mathrm{C}$ corresponding to a hot spot and $32.0^{\circ} \mathrm{C}$ corresponding to a healthy area of the panel. Figure $2 b$ shows the visible light image taken with the same camera.

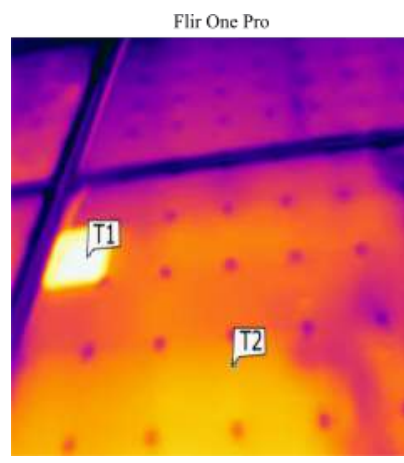

(a)

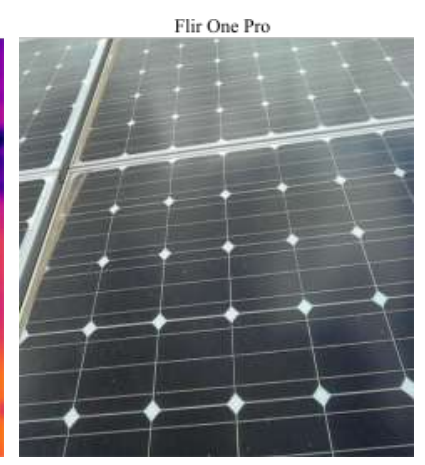

(b)
Figure 2 Thermal image of a PV panel captured by a FLIR One Pro camera. (a) IR thermal image (b) visible light image for reference

Table 5 shows metadata obtained from images taken with the Flir One Pro. This metadata corresponds to the temperature of each pixel in the image. This data allows temperature analysis of each point of the image. Similar data is obtained with the Cat S60 camera. For the Cat S60 camera a $240 \times 320$ matrix was found, while the Flir One Pro delivered a $480 \times 640$ matrix.

Other alternatives do not provide metadata on the images (as the Flir TG167 camera). This makes necessary the use of image processing techniques to estimate the temperature based on color intensity or rely on the embedded microbolometer sensor to display the temperature of a point in the image.

\subsection{Thermal image analysis and temperature tables}

Analyzing the solar panel with anomalies, three points of interest were identified: the defective cell (T1), the unaffected area (T2) and the junction box (T3, see Figure 3). This image corresponds to the second panel with a hot spot. Using the Flir One Pro and the Cat S60 cameras, these points were identified as T1, T2 and T3 with temperatures of $51.3^{\circ} \mathrm{C}, 35.3^{\circ} \mathrm{C}$ and $35.2^{\circ} \mathrm{C}$ respectively.

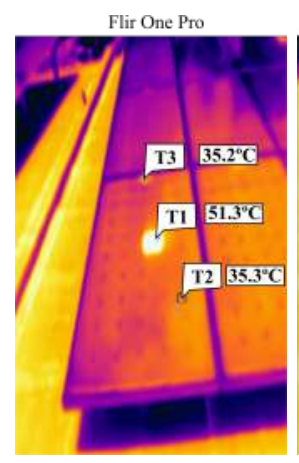

(a)

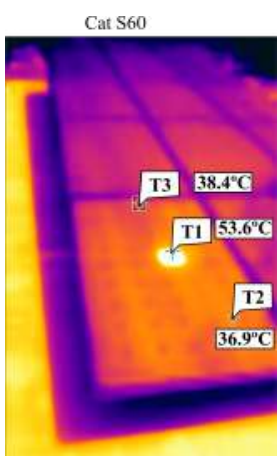

(b)

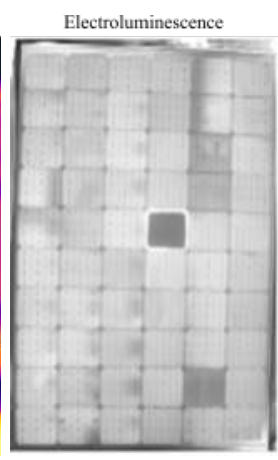

(c)
Figure 3 Thermal image of a defective PV panel captured by (a) Flir One Pro camera (b) Cat S60 camera (c) Electroluminescence image for comparison

On Figure 3a, using a Flir One Pro camera, the temperature difference found between the faulty cell and an unaffected area of the panel was $\Delta \mathrm{T}=15.9^{\circ} \mathrm{C}$ with a maximum temperature of $52^{\circ} \mathrm{C}$ on the damaged cell. Studies indicate that a temperature of $51.3^{\circ} \mathrm{C}$ reached on the cell could be considered as a major fault [8], so short term maintenance is required. Also, according to [4] the value obtained indicates a "medium failure". Figure 3b shows same three points $\mathrm{T} 1, \mathrm{~T} 2$, and $\mathrm{T} 3$, with temperatures of $53.6^{\circ} \mathrm{C}, 36.9^{\circ} \mathrm{C}$, and $38.4^{\circ} \mathrm{C}$ respectively, but image was captured using a CAT S60 camera. Here the temperature difference between $T 2$ and $T 3$ reaches $\Delta T=14.8^{\circ} \mathrm{C}$, with a maximum temperature of the image of $53.2^{\circ} \mathrm{C}$, so major 
Table 5 Metadata of Figure 2a, obtained from a Flir One Pro camera. (rows and columns headers are only for reference)

\begin{tabular}{cccccc}
\hline Row/column & Pixel [1,2] & Pixel [1,3] & Pixel [1,4] & Pixel [1,5] & Pixel [1,n] \\
\hline Pixel [2,1] & 25.331 & 25.331 & 25.331 & 25.331 & $\ldots$ \\
\hline Pixel [3,1] & 25.338 & 25.338 & 25.338 & 25.338 & $\ldots$ \\
\hline Pixel [4,1] & 25.354 & 25.354 & 25.354 & 25.346 & $\ldots$ \\
\hline Pixel [5,1] & 25.376 & 25.376 & 25.376 & 25.369 & $\ldots$ \\
\hline Pixel [6,1] & 25.407 & 25.407 & 25.399 & 25.392 & $\ldots$ \\
\hline Pixel [7,1] & 25.437 & 25.437 & 25.43 & 25.422 & $\ldots$ \\
\hline Pixel [8,1] & 25.468 & 25.46 & 25.46 & 25.445 & $\ldots$ \\
\hline$\ldots$ & $\ldots$ & $\ldots$ & $\ldots$ & $\ldots$ & $\ldots$ \\
\hline
\end{tabular}

or medium failure criteria is also considered. Figure $3 c$ shows an electroluminescence image of the panel, where a completely dark cell with illuminated edges is clearly seen.

Four types of graphs were used to verify the application of low-cost thermal cameras: intensity graph, X-Y dispersion, 3D mesh, and 3D mesh contour. The intensity graph is based on the reconstruction of the values of the metadata table, the $X-Y$ dispersion allows to observe the maximum and minimum values of the image, the $3 \mathrm{D}$ mesh allows to observe the three-dimensional distribution of the temperature levels, and the 3D mesh contour allows to see if the hot spot can be distinguished between the other elements of the image. Therefore, an intensity graph was reconstructed (Figure 4) using the temperature table obtained from the metadata of the images, where, each pixel is given by Equation 1:

$$
\text { pixel }=(\text { Xposition }, Y \text { position, temperature })
$$

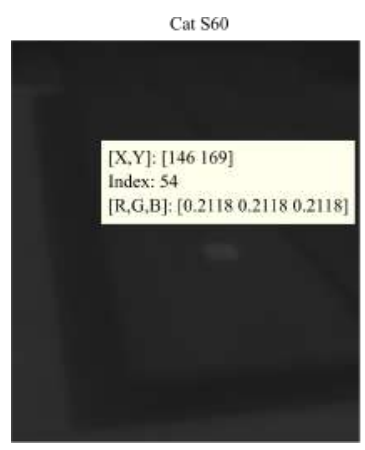

(a)

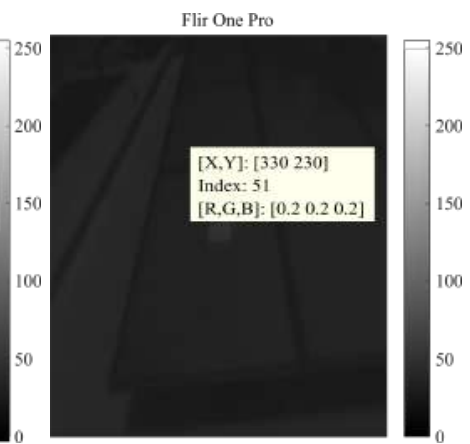

(b)
Figure 4 Image reconstructed from the temperature table (a) Flir One Pro camera (b) Cat S60 camera

The intensity graph in Figure 4 might be confused with a grayscale image, however a grayscale algorithm was not used, instead, it is the direct graph of the pixel intensity information obtained from the metadata of the image captured by the thermal camera. This presents an important advantage because the exact temperature of each element in the image can be obtained without the need for any type of image processing.

An $X-Y$ graph consisting of the $X$ coordinate of the pixel and the temperature on the $Y$ axis, was made using data from Figure 4 in Matlab ${ }^{\circledR}$ (see Figure 5), where the dispersion of the temperature values is obtained, identifying the maximum temperature corresponding to the faulty cell con the panel, in this case $52^{\circ} \mathrm{C}$, and the maximum temperature of $43^{\circ} \mathrm{C}$ for the highest temperature of an unaffected area. This leads to a value of $\Delta \mathrm{T}=9^{\circ} \mathrm{C}$, according to [4] this could mean a "light failure".

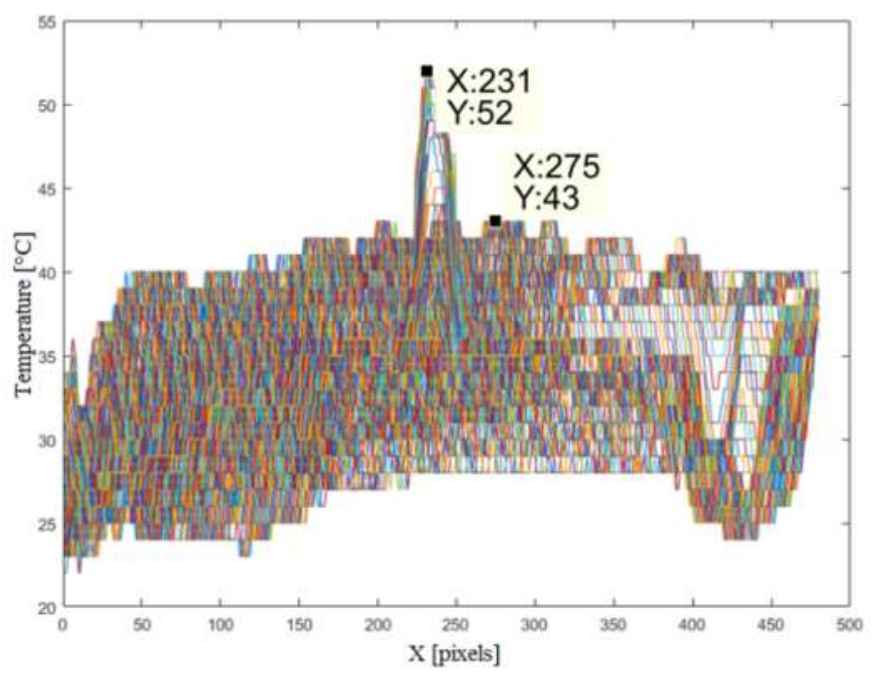

Figure $5 \mathrm{X}-\mathrm{Y}$ dispersion of the thermal image of the panel with a hot spot

Figure 6 shows the representation of the temperature of the panel with a hot spot in a three-dimensional mesh. The arrangement of the thermal intensities can be observed, allowing to easily identify the hottest point of the image.

Also, on Figure 7, a contour analysis of the temperature data is observed. Contour shows the projection of Figure 6 Z-axis (temperatures) on a two-dimensional image. This analysis can be used as an edge detection approach to identify faulty cells. 


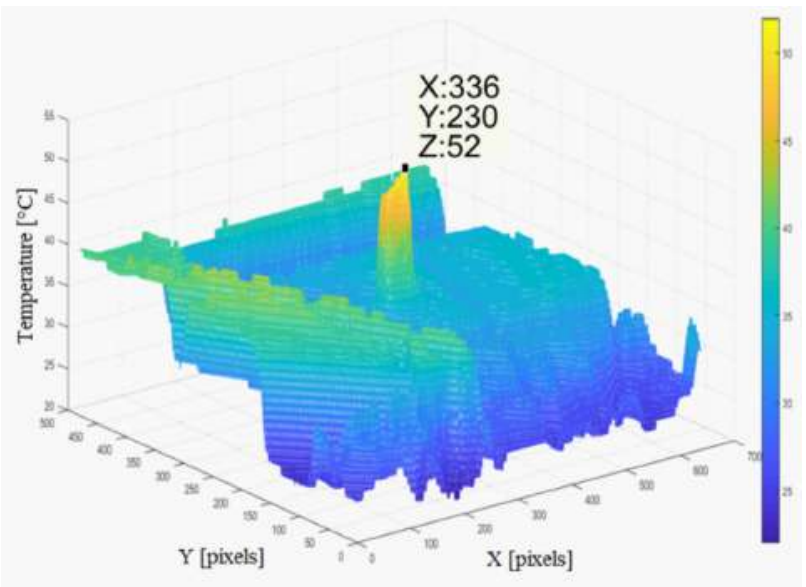

Figure 6 A three-dimensional mesh of the thermal image of the panel with a hot spot

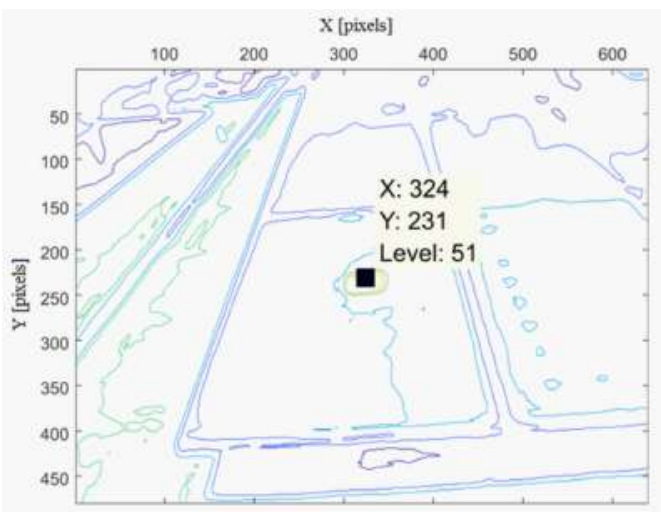

Figure 7 The contour of the three-dimensional mesh of the thermal image

\subsection{Static image analysis}

A static Image is determined as images from thermal cameras without metadata, but generally manufacturers provide a color map (sidebar that indicates the relationship between the color of the image and the temperature) as a reference of the temperature of each pixel (see Figure $8 \mathrm{a}$ and Figure $8 \mathrm{~b}$ ). This type of images is common in low-cost cameras and IR thermometers. As low-cost is the aim of this paper, static images analysis is studied to observe their validity in thermography of PV solar panels.

In order to obtain the estimated pixel temperature, the image is initially converted to grayscale, and then the intensity values are normalized to find the new pixel value using Equation 2:

Temperature $_{\text {pixel }}=T_{\min }+\left(T_{\max }-T_{\min }\right) x$ Intensity

The grayscale image obtained is shown in Figure 9. The new pixel intensity values correspond to a normalized temperature.

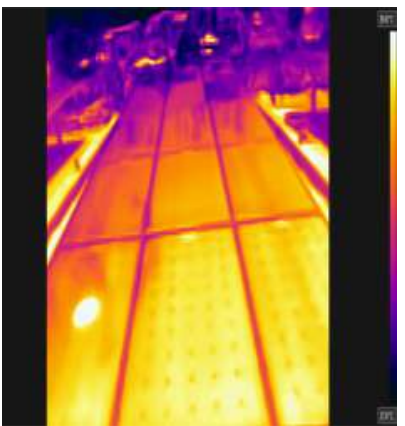

(a)

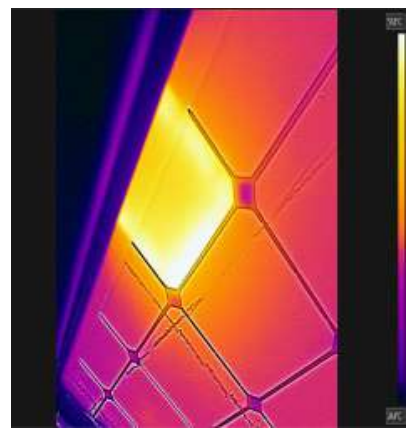

(b)
Figure 8 Static image obtained from a thermal camera with the color map on the right side. (a) PV String with one panel with a hot spot (b) defective cell thermal image obtained from the back of the panel
Cat $\mathrm{S} 60$

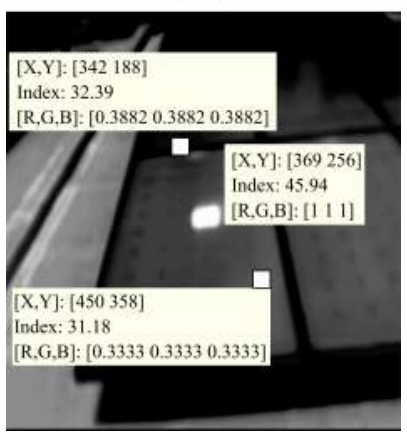

(a)
Flir One Pro

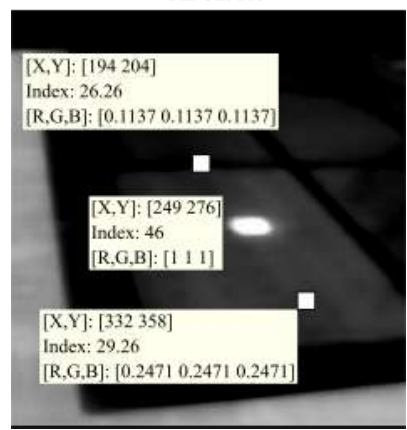

(b)
Figure 9 Standard grayscale static image showing pixel temperature (a) Flir One Pro (b) Cat S60

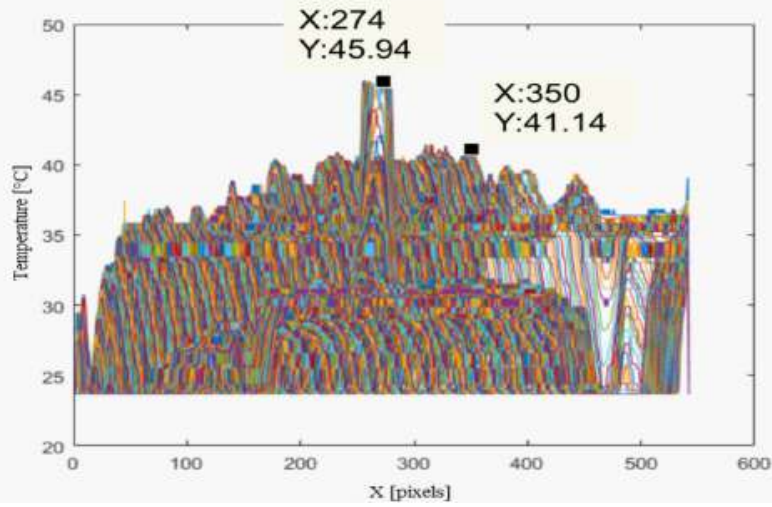

Figure 10 Dispersion of the static image obtained from a Flir One Pro camera

An $X Y$ scatter plot is shown in Figure 10, where the maximum pixel temperature can be found $\left(45.94^{\circ} \mathrm{C}\right)$, however, a loss of details due to the normalization can be observed causing a decrease in accuracy. It is also observed that the amplitude of the pixel values increases for areas other than the faulty cell and that there are more 
pixels with low temperatures. This behavior is caused due to image normalization and limitations on the image filetype format (jpeg).

Repeating the procedure for the three-dimensional mesh in the static image Figure 11 is obtained. A similar behavior was found for the thermal image obtained with a Cat $\mathbf{S 6 0}$ camera, with the difference in the maximum temperature achieved, and in the same way as in the $X Y$ scatter plot (dispertion), a greater amount of values are observed in the base of the graph within the lower range of temperatures of the image.

Finally, by repeating the contour of the mesh, Figure $12 \mathrm{a}$ is obtained. It is observed that, due to the normalization of the image, there are marked areas of the temperature gradient that can interfere or make it difficult to use geometry identification algorithms in image processing, this variation between the different techniques is shown in Figure $12 \mathrm{~b}$.

\subsection{Static images without color map}

Thermal cameras or specifically Infrared Thermometers with thermal cameras like de Flir TG167 do not provide a color map nor temperature tables as the other low-cost IR thermal cameras discussed in this paper. Nevertheless, they can provide useful information and be able to detect hot spots in PV panels. Figure 13 shows thermal images obtained with this camera. It is observed that the cell with anomalies is clearly differentiated from an unaffected area. The image shown corresponds to a different measurement, and as this type of thermal camera does not provide more data from the temperature pattern, it is not considered in the error calculation.

\subsection{I-V/P-V curves analysis as first validation}

To validate that the cameras used in this study are capable of identifying a fault in a PV panel, I-V/P-V curves of the PV panel with a faulty cell where obtained using a Solmetric PVA-600 tracer [12]. Panels with hot spots or faulty cells reduce their power output and I-V/P-V curves differs from unaffected panels. PV panel found with a hot spot is an ATERSA A-250P monocrystalline panel [13]. Figure 14 shows I-V and P-V curves of the panel that has a hot spot and a panel without faults as a comparison. It is observed that the voltage of the panel with failure falls at around $16 \mathrm{Vdc}$, showing a typical behavior of a damaged or "shaded" cell [14-17] which matches the thermography image. Reviewing the P-V curve of the panels, the decrease in the maximum power point (MPP) is observed, power decreases from $94.16 \mathrm{~W}$ on the panel without anomalies (see Figure 14a), to $69.97 \mathrm{~W}$ on the panel with anomalies (with a hotspot, see Figure 14b) obtaining a $25.69 \%$ less power in the panel with the hot spot compared to a panel without failures.

\subsection{Temperature sensor matrix as second validation}

As a second validation method, in order to verify the temperature measurement error, a sensor matrix was employed (see Figure 15a) to determine a faulty cell temperature. DS18b20 temperature sensors were used to obtain the cell real temperature (see Figure 15b), whit this an average value of $57.98^{\circ} \mathrm{C}$, on the other hand, using a Flir TG167 a value of $51.6^{\circ} \mathrm{C}$ was obtained (see Figure 15c), and using the CAT S60 camera and the Flir Tools software (see Figure $15 \mathrm{~d}$ ), a temperature of $63.1^{\circ} \mathrm{C}$ was obtained, that is a $5^{\circ} \mathrm{C}$ error. A similar error was obtained for the Flir One Pro camera and the Flir TG167.

\subsection{UAV and low-cost camera test}

Inspections with low-cost cameras can be carried out with the help of remote-operated mobile systems. Further information about this kind of onboard thermal inspections can be found in $[18,19]$. In this research, the behavior of the Cat S60 camera is tested. The camera was mounted on a DJI Mavic Pro drone (Figure 16a) and used as proof of concept in order to verify that this camera can show the hot spot on the faulty panel. Figure $16 \mathrm{~b}$ was obtained by flying the drone at three meters above the panel. It is noted that the hot spot in the image can be clearly identified. However, this camera does not deliver a heat map or a temperature table in video capture mode, so its use should be limited to manual hot spots detection.

\subsection{Results}

Table 6 shows the temperature average values of the PV panel with a hotspot, obtained with the three low-cost cameras, and the relative errors between cameras. The temperatures obtained from the thermal image and the static image are shown, as well as the absolute measurement error based on the measurement with the sensor matrix, and the relative error between cameras. It is observed that in the image analysis a relative error of $10.45 \%$ is obtained for the measured temperature of the faulty cell, and a relative error of $7.75 \%$ for $\Delta T$ between the cell and an unaffected area. For the analysis of the $X-Y$ dispersion, an error of $46.67 \%$ is observed for the faulty cell, while for the mesh analysis there is an $11.54 \%$ error and for the three-dimensional contour a $9.80 \%$ error. This indicates that contour analysis and mesh analysis are better candidates than dispersion analysis in image processing in cases where the temperature table is not available. 


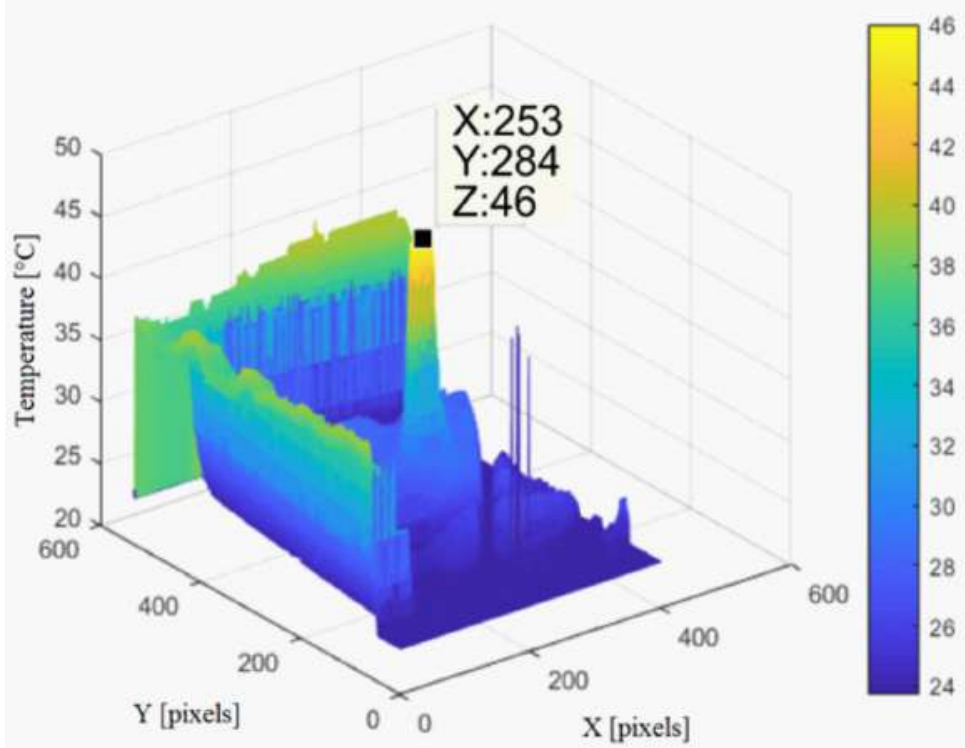

Figure $11 \mathrm{~A}$ three-dimensional mesh of the static image of the panel with a hot spot obtained from the Cat S60 camera

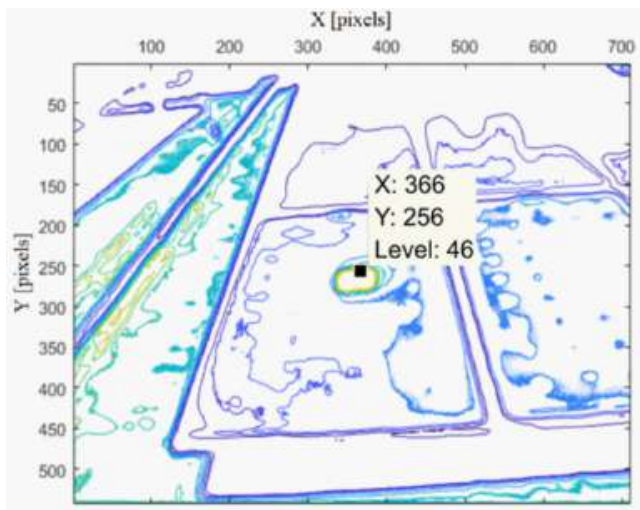

(a)

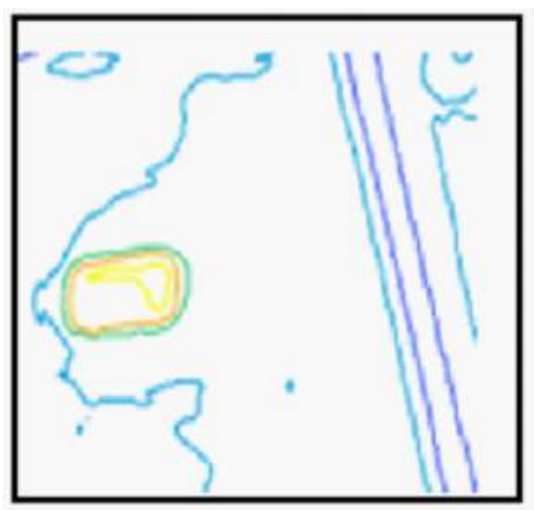

(b)

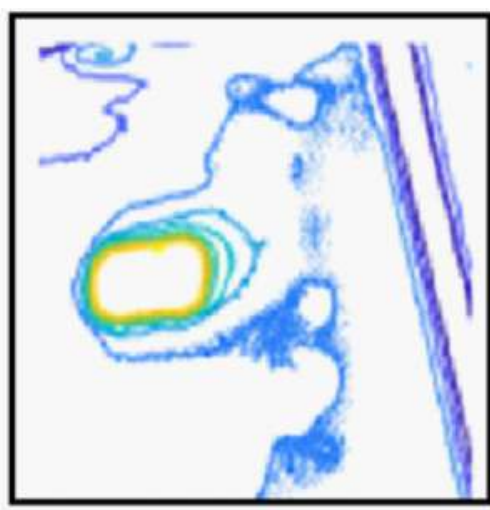

Figure 12 The contour of the three-dimensional mesh of the panel with hot spot (a) obtained from the static image, (b) comparison between thermal image contour (left) and static image (right)

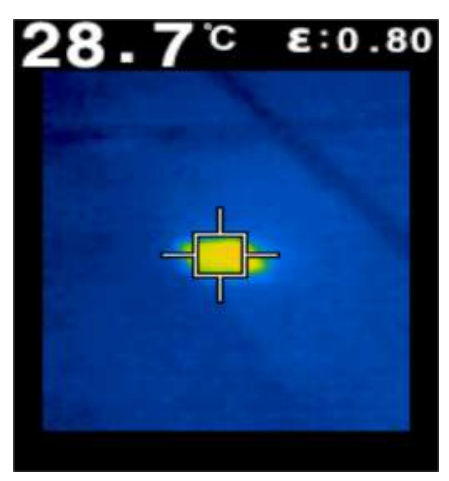

(a)

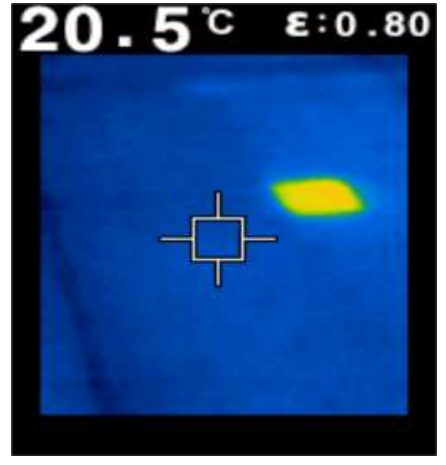

(b)

Figure 13 Thermal images from a Flir TG167 camera (a) hot spot detected and temperature obtained, (b) PV panel area without anomalies and temperature obtained 


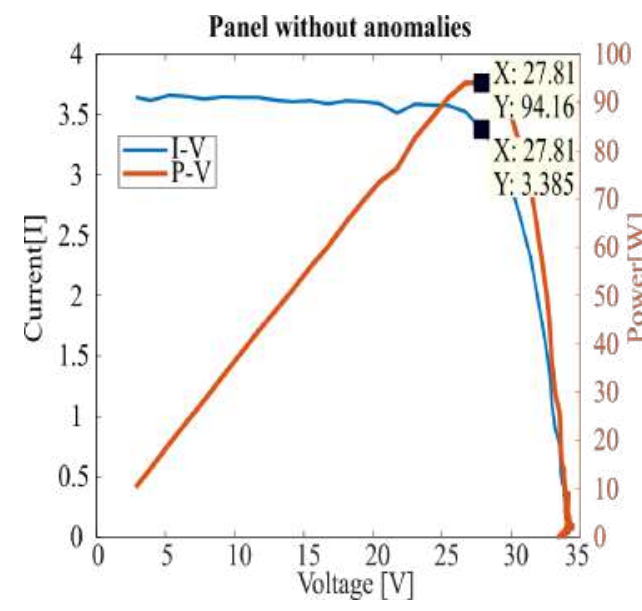

(a)

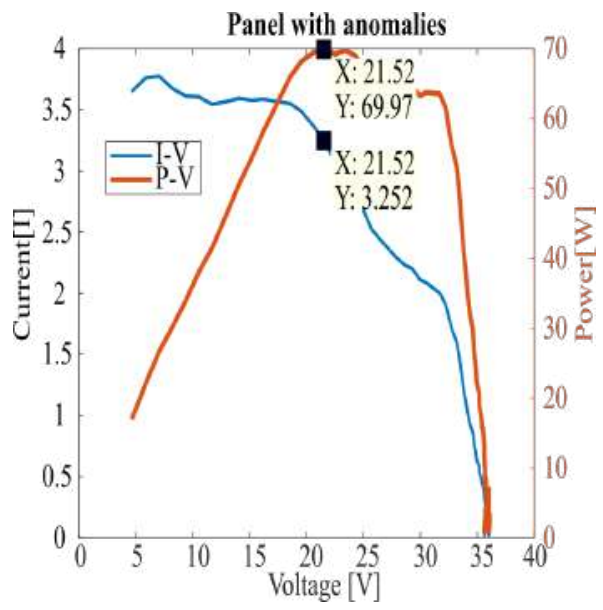

(b)

Figure 14 Characteristic curves of the panel with failure and another without anomalies (a) Panel without anomalies (b) Panel with anomalies

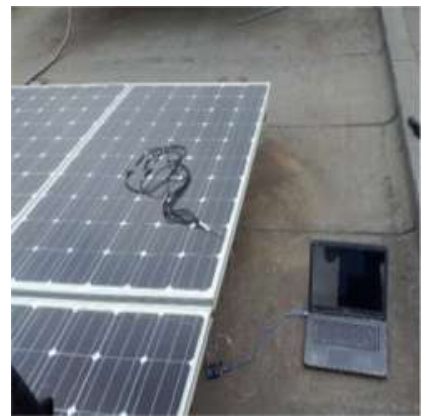

(a)

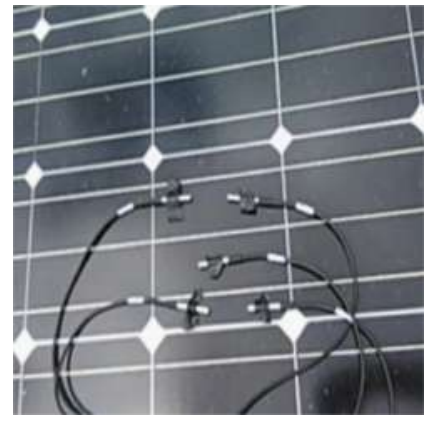

(b)

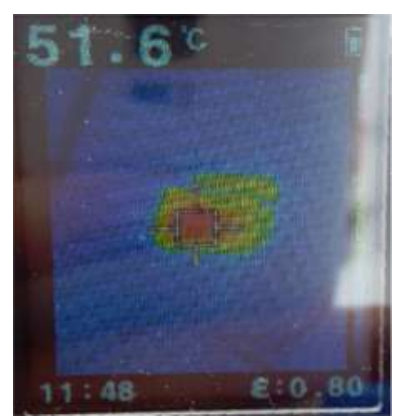

(c)

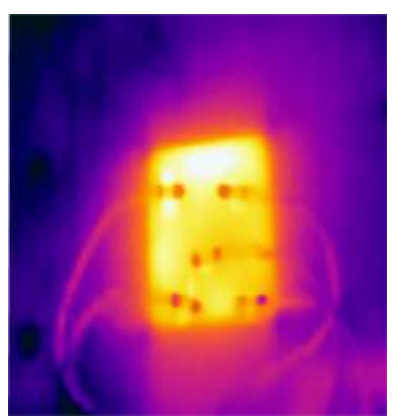

(d)

Figure 15 Temperature sensor matrix validation (a) Logging setup (b) Sensors deployed (c) Flir TG167 measurement (d) Cat S60 thermal image

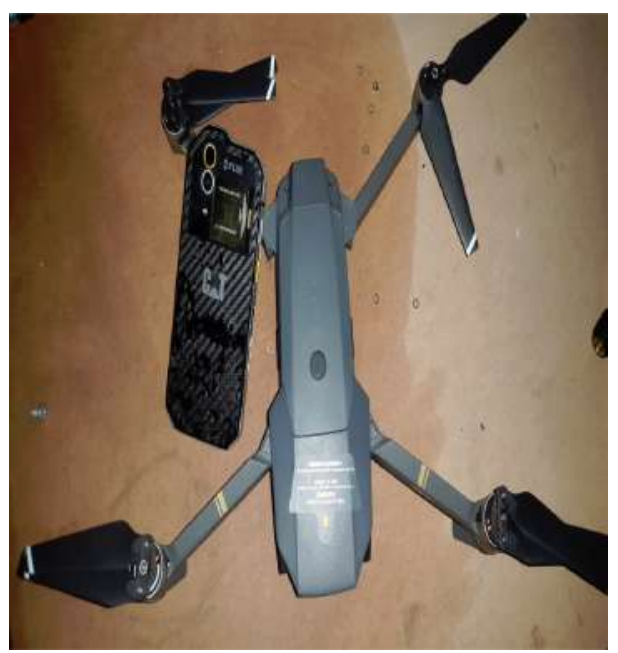

(a)

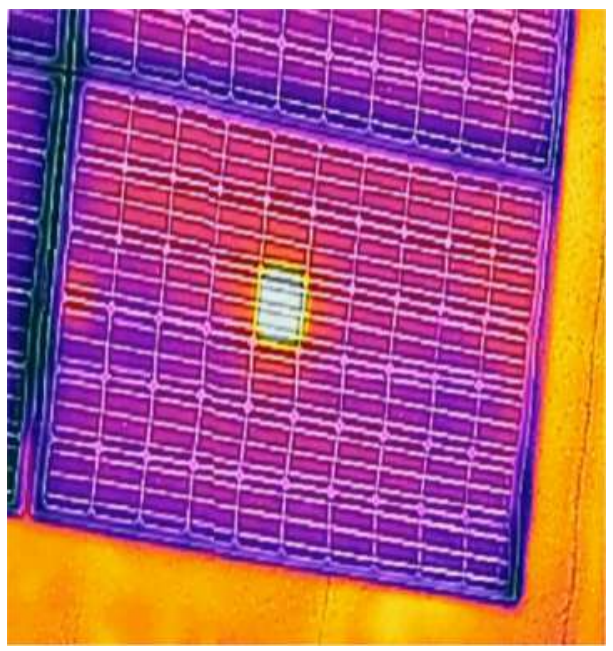

(b)

Figure 16 Solar panel thermography with drone (a) Cat s60 thermal camera and DJI Mavic Pro drone (b) captured image 
Table 6 Results from comparison between cameras

\begin{tabular}{c|cccc}
\multirow{2}{*}{ Parameter } & Thermal image & Static image & Absolute error & Relative error \\
\cline { 2 - 5 } & \multicolumn{4}{|c}{ Single image value obtained } \\
\hline Connection box & $35.20^{\circ} \mathrm{C}$ & $32.39^{\circ} \mathrm{C}$ & $2.81^{\circ} \mathrm{C}$ & $7.98 \%$ \\
\hline Panel & $35.30^{\circ} \mathrm{C}$ & $31.18^{\circ} \mathrm{C}$ & $4.12^{\circ} \mathrm{C}$ & $11.67 \%$ \\
\hline Faulty cell & $51.30^{\circ} \mathrm{C}$ & $45.94^{\circ} \mathrm{C}$ & $5.36^{\circ} \mathrm{C}$ & $10.45 \%$ \\
\hline$\Delta$ T faulty cell & $16.00^{\circ} \mathrm{C}$ & $15.00^{\circ} \mathrm{C}$ & $1.24^{\circ} \mathrm{C}$ & 7.75 \\
\hline & \multicolumn{4}{|c}{$\mathrm{X}-\mathrm{Y}$ dispersion Graph } \\
\hline$T_{\max }$ faulty cell & $52.00^{\circ} \mathrm{C}$ & $45.94^{\circ} \mathrm{C}$ & $6.06^{\circ} \mathrm{C}$ \\
\hline$T_{\max }$ adjacent área & $43.00^{\circ} \mathrm{C}$ & $41.14^{\circ} \mathrm{C}$ & $1.86^{\circ} \mathrm{C}$ \\
\hline$\Delta \mathrm{T}$ faulty cell & $9.00^{\circ} \mathrm{C}$ & $4.80^{\circ} \mathrm{C}$ & $4.20^{\circ} \mathrm{C}$ & $4.33 \%$ \\
\hline & \multicolumn{5}{|c}{$3 \mathrm{D} \mathrm{Mesh}$} \\
\hline$T_{\max }$ faulty cell & $2.00^{\circ} \mathrm{C}$ & $46.00^{\circ} \mathrm{C}$ & $6.00^{\circ} \mathrm{C}$ \\
\hline$T_{\max }$ faulty cell & $51.00^{\circ} \mathrm{C}$ & $46.00^{\circ} \mathrm{C}$ & $11.54 \%$ \\
\hline
\end{tabular}

The errors observed in dispersion and contour analysis are less than $10 \%$, so they can be used in the thermographic analysis by extrapolating the temperature [20]. Previous studies [21-23] show that the error can be improved with image processing techniques and neural networks.

\section{Conclusions}

This paper presents a description of the characteristics of low-cost thermal imaging cameras, emphasizing its cost/resolution relationship. It is observed that the analysis of thermography using low-cost cameras is viable considering the established errors, which can be less than $10 \%$. Hot spot detection with low-cost IR thermal cameras is validated using I-V/P-V curves.

From the analysis of static images, it is shown that a three-dimensional contour is a valid tool with less than $10 \%$ error, which can be improved with artificial intelligence techniques and neural networks.

The thermal cameras used in this document cost less than $10 \%$ of high-end cameras, without compromising the detection of hot spots in PV panels, which allows these low-cost cameras to be used in thermographic studies considering the limitations in terms of their construction and their feasibility of outdoor use.

\section{Declaration of competing interest}

We declare that we have no significant competing interests including financial or non-financial, professional, or personal interests interfering with the full and objective presentation of the work described in this manuscript.

\section{Acknowledments}

We would like to thank the CEDER by providing information for the development of this work. The authors thank the CYTED Thematic Network "CIUDADES INTELIGENTES TOTALMENTE INTEGRALES, EFICIENTES Y SOSTENIBLES (CITIES)" no518RT0558.

\section{References}

[1] R. Usamentiaga and et al, "Infrared thermography for temperature measurement and non-destructive testing," Sensors (Basell, vol. 14, no. 7, July 2014. [Online]. Available: https://doi.org/10.3390/ s140712305

[2] K. Delac and M. Grgic, "Detecting hot spots in photovoltaic panels using low-cost thermal cameras," in Ibero-American Congress on Information Management and Big Data (ICSC-CITIES 2019), 2019, pp. 38-53.

[3] P. Battalwar, J. Gokhale, and U. Bansod, “Infrared thermography and IR camera," Int. J. Res. Sci. Eng, vol. 1, no. 3, pp. 9-14, 2015.

[4] E. Ruggeri, B. B. Van, O. Isabella, and M. Zeman, "Electroluminescence and dark lock-in thermography for the quality assessment of metal-wrap-through solar devices," IEEE Journal of Photovoltaics, vol. 8, no. 5, September 2018. [Online]. Available: https://doi.org/10.1109/JPHOTOV.2018.2850530

[5] C. Toledo, L. Serrano, J. Abad, A. Lampitelli, and A. Urbina, "Measurement of thermal and electrical parameters in photovoltaic systems for predictive and cross-correlated monitorization," Energies, vol. 12, no. 4, February 2019. [Online]. Available: https://doi.org/10.3390/en12040668

[6] R. L. Do Santos, J. S. Ferreira, G. E. Martins, K. C. de Souza, and E. M. Sá, “Low cost educational tool to trace the curves PV modules," IEEE Latin America Transactions, vol. 15, no. 8, January 2017. [Online]. Available: https://doi.org/10.1109/TLA.2017.7994784

[7] M. Dhimish, V. Holmes, B. Mehrdadi, M. Dales, and P. Mather, “PV output power enhancement using two mitigation techniques for hot spots and partially shaded solar cells," Electr. Power Syst. Res., vol. 158, May 2018. [Online]. Available: https://doi.org/10.1016/j.epsr. 2018.01.002

[8] M. Dhimish and V. Holmes and B. Mehrdadi and M. Dales and P. Mather, "Design and implementation of a photovoltaic I-V curve tracer: Solar modules characterization under real operating 
conditions," Energy Convers. Manag., vol. 169, August 12018. [Online]. Available: https://doi.org/10.1016/j.enconman.2018.05.046

[9] Z. A. Jaffery, A. K. Dubey, Irshad, and A. Haque, "Scheme for predictive fault diagnosis in photovoltaic modules using thermal imaging," Infrared Phys. Technol., vol. 83, June 2017. [Online]. Available: https://doi.org/10.1016/j.infrared.2017.04.015

[10] A. M. Salazar and E. Q. Macabebe, "Hotspots detection in photovoltaic modules using infrared thermography," MATEC Web of Conferences, vol. 70, January 2016. [Online]. Available: https://doi.org/10.1051/matecconf/20167010015

[11] J. L. Espinoza, L. G. Gonzalez, and R. Sempertegui, “Micro grid laboratory as a tool for research on non-conventional energy sources in Ecuador," in 2017 IEEE International Autumn Meeting on Power, Electronics and Computing (ROPEC), Ixtapa, Mexico, 2017.

[12] FLIR® Systems, Inc. Thermal analysis and reporting (desktop)FLIR tools. [FLIR Systems, Inc.]. Accessed Nov. 14, 2019. [Online]. Available: https://bit.ly/2TOlRNu

[13] Solmetric Corporation. (2010) Solmetric PVA-600 PV Analyzer User's Guide. Solmetric Corporation. [Online]. Available: https: //bit.ly/3cfmwhw

[14] Athersa. (2019) Paneles solares policristalinos. [Athersa Shop]. Accessed Nov, 2019. [Online]. Available: https://bit.ly/3gKFa4r

[15] N. Kawasaki, "Energía fotovoltaica, trazador de curvas V-I para seguimiento de módulos solares," Undergraduate degree, Departamento de Sistemas Energéticos, Universidad Politécnica de Madrid, Madrid, España, 1996.

[16] A. Hemza, H. Abdeslam, C. Rachid, and N. Aoun, “Simplified methods for evaluating the degradation of photovoltaic module and modeling considering partial shading," Meas. J. Int. Meas. Confed., vol. 138, February 2019. [Online]. Available: http://dx.doi.org/10. 1016/j.measurement.2019.01.098

[17] J. E. Quiroz, J. S. Stein, C. K. Carmignani, and K. Gillispie, "In-situ module-level I-V tracers for novel PV monitoring," in 2015 IEEE 42 ${ }^{\text {nd }}$ Photovoltaic Specialist Conference (PVSC), New Orleans, LA, USA, 2015.

[18] K. A. Kim, G. S. Seo, B. H. Cho, and P. T. Krein, "Photovoltaic hot-spot detection for solar panel substrings using AC parameter characterization," IEEE Trans. Power Electron., vol. 31, no. 2, February 2016. [Online]. Available: http://dx.doi.org/10.1109/TPEL. 2015.2417548

[19] S. Gallardo, L. Hernandez, and O. Duque, "Image resolution influence in aerial thermographic inspections of photovoltaic plants," IEEE Trans. Ind. Informatics, vol. 14, no. 12, December 2016. [Online]. Available: http://dx.doi.org/10.1109/TII.2018.2865403

[20] W. Zaaiman. (2012) Solar irradiance and photovoltaic measurements from solar radiation to PV arrays. European Commission, Joint Research Center. Ispra, ITL.

[21] W. Chine and et al, "A novel fault diagnosis technique for photovoltaic systems based on artificial neural networks," Renew. Energy, vol. 90, May 2016. [Online]. Available: https://doi.org/10. 1016/j.renene.2016.01.036

[22] R. Koprowski, "Some selected quantitative methods of thermal image analysis in Matlab," J. Biophotonics, vol. 9, no. 5, May 2016. [Online]. Available: https://doi.org/10.1002/jbio.201500224

[23] J. A. Tsanakas, L. Ha, and C. Buerhop, "Faults and infrared thermographic diagnosis in operating $\mathrm{c}-\mathrm{Si}$ photovoltaic modules: A review of research and future challenges," Renewable and Sustainable Energy Reviews, vol. 62, September 2016. [Online]. Available: https://doi.org/10.1016/j.rser.2016.04.079 